\title{
Outcomes of with open and Seldinger- Guided Peripheral Cannulation Techniques in open heart surgery
}

\author{
Tuğra Gençpınar ${ }^{1}$, Ceren Sayarer $^{2}$, Gökmen Akkaya $^{1}$, Öztekin Oto ${ }^{3}$
}

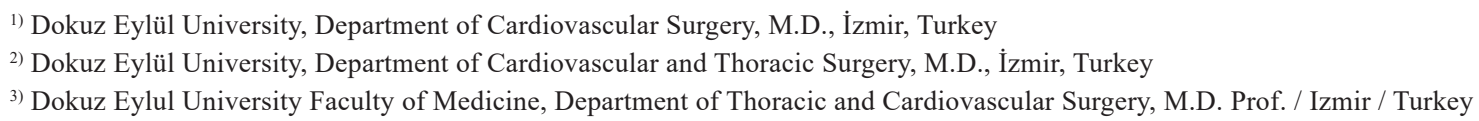

\begin{abstract}
Objective: In this study, we evaluated the results of open access and seldinger guided peripheral cannulation techniques in patients which underwent open heart surgery.

Materials and Method: The results of heart surgery cases with peripheral artery and vein open access technique and seldinger guide technique between November 2010 and October 2017 were evaluated retrospectively. Edwards ${ }^{\circledR}$ Fem-Flex II and Medtronic Bio-Medicus ${ }^{\mathrm{TM}}$ NextGen percutaneous femoral artery and venous Cannulas were chosen. Peripheric cannulations were performed percutaneously with doppler ultrasonography via guided seldinger technique. Seldinger technique for peripheric cannulation was preferred even open exploration of the groin vessels were needed.

Results: 65 patients (32 male, 33 female; mean age $43 \pm 37$ years; range 3-81 years) were taken into the study that peripheral cannulation performed. In 18 (27.6\%) patients minimally invasive technique was applied and $34(52.3 \%)$ patients were redo cases. A mean flow of 4,108 $\pm 0.6 \mathrm{~m} 21 / \mathrm{m} 2 / \mathrm{m}$ was achieved with vacuum application in only 6 patients $(9.2 \%)$ for venous drainage. No hemothorax, pneumothorax or hematoma had occured in cannulation sites due to internal jugular vein or femoral cannulations. Surgical embolectomy was performed due to distal thrombus only in 4 patients $(6.15 \%)$ to whom had conventional cannulation. In 4 patients $(6.15 \%)$ femoral venous cannula couldn't reached up to the right atrium.
\end{abstract}

Conclusion: In our opinion, seldinger technique either performed percutaneously or surgically is a faster, easier and superior technique in protecting distal limb perfusion when compared with open vasculotomy with proximal/distal clamping technique. Moreover, it can be safely applied in high risk redo cases as well as routine minimally invasive surgery.

Key Words: Cannulation; extracorporeal circulation; seldinger guide; minimally invasive; percutaneous. 


\section{Introduction}

Recently peripheral artery and vein cannulation technique has become popular since the numbers of minimally invasive heart surgeries and redo cases are increasing. After a limited learning curve for the peripheric cannulation and application of vacuum to venous lines when is needed, efficient cardiopulmonary bypass can always be achieved. Implication of cannulation with percutaneous cannulas in peripheric veins and arteries is an innovation that eases the workload of surgeon in minimally invasive and redo cases. By means of percutaneous peripheric cannulation, extracorporeal circulation (CPB) can be even applied before the sternotomy to reduce the tension of massively adhered heart tissues underneath the sternum in order to overcome the possible perforation problems during the resternotomy if occures.

Peripheric cannulation provides an advantage in cases with minimally invasive heart surgery, heart transplant, high risk redo cases, robotic heart surgery and cardiopulmonary resuscitation (CPR) that requires extracorporeal membrane oxigenator (ECMO). ${ }^{(4-6)} \mathrm{Ad}$ ditionaly It is known that femoral artery cannulation and retrograd perfusion is safe and doesn't increase stroke rate. ${ }^{(1-3)}$ Femoral artery cannulation is preferred in emergency cases, redo cases and minimally invasive heart surgeries. Axillary artery cannulation with antegrad perfusion is preferred especially in thoracic aort and redo surgeries. ${ }^{(4-6)}$

Besides, small diameter of axillary artery can complicate the placement of antegrad perfusion cannule. Jugular vein cannulation can provide venous return in minimally invasive heart surgeries and redo cases. Internal jugular vein (İJV), femoral, axillary, subclavian and iliac vessels can be used for peripheric cannulation. ${ }^{(1-37)}$ Seldinger guide technique provides ease of implantation in both arterial and venous cannulation in comparison to concervative surgical procedure.

Decannulation can be performed more quickly. In redo cases, implication of CPB before sternotomy can decrase mortality and morbidity. In this study, the results of percutan and open peripheric cannulation techniques in open heart surgery were evaluated.

\section{Material and Method}

The results of heart surgery cases with peripheral artery-vein open surgery technique and seldinger guide technique between November 2010 and June 2017 were evaluated retrospectively.

Dokuz Eylul University ethics comitee permission (date: 04.08.2016, protocol: 2841-GOA) and necessary permissions to get and use archieve datas (anesthesia and perfusion records, electronic records) were obtained.

The cases that include use of central cannulation because of changing strategy, urgent patients, infective endocarditis cases and the patients that had performed CPR and ECMO were excluded from the study. The outcomes of open surgery technique and seldinger guide technique for peripheric cannulation were evaluated as well as patients demographic datas.

\section{Technique}

All patients were operated under general anesthesia and endotracheal entubation. For patients that had been planned right jugular venous cannulation, $7 \mathrm{~F}$ three way central venous cathether (Certofix Trio V720) using left IJV and 20G (Becton Dickinson insyte cannula, Swindon, UK) artery cathether using left radial artery were placed before extracorporeal circulation. For right IJV cannulation, patients were positioned as right arm closed and shoulder elevated approximately $5 \mathrm{~cm}$. Patients were prepared properly and covered with sterile clothes.

Anaesthesiologist had also scrubbed and involved the operation site. Pump lines were taken into the surgery region. IJV and femoral artery and vein were evaluated for atherosclerosis, mobile thrombus, occlusion and diameter via doppler ultrasonography. For percutanous jugular vein cannulation, ponction site was marked preoperatively. For patients whom had percutanous right IJV cannulation plan, IJV ponction was maden in trendelenburg position and guidewire was placed into vein via seldinger technique (Figure 1). 1.5 $\mathrm{mg} / \mathrm{kg}$ heparin was administered for partial anticoagulation. After dilatation, Edwards ${ }^{\circledR}$ Lifesciences Fem Flex II or Medtronic Bio-Medicus ${ }^{\mathrm{TM}}$ NextGen percu- 
tanous femoral cannule was placed into right IJV. 16 Fr cannules were used for patients to whom body surface area is under $1.7 \mathrm{~m} 2,18 \mathrm{Fr}$ cannules were used for patients whom body surface area is above $1.7 \mathrm{~m} 2$. Cannules advanced approximately to right atrium entrance $(10-15 \mathrm{~cm})$ and fixed to skin. Following the flow rate was checked with aspiration, cannules were clamped. According to surgical plan, clamps were removed and providing a full return, 4/1/min flow rate was maintained during CPB.

For femoral artery and vein cannulation, vessels were explored with $2 \mathrm{~cm}$ vertical incision, $1 \mathrm{~cm}$ blow to the inguinal ligament. Main femoral artery and vein surrounded and taped for bleeding control. Vessels were fixed with a silk suture to the skin.

In standart surgical cannulation planned cases, cannulation was made with arteriotomy after heparinization. Patients were taken into temporary CPB in order to check perfusion and cannulas were fixed (Figure 2). We chose right femoral cannulation because of its nearest position to the surgeon and easy to manupilate.

For patients whom planned minimally invasive surgery, aortic cross clamp was placed to ascending aorta using standard X clamps. Cardioplegia was administered through aortic root using standard cannulas. For de-airing, patient turned around to right side and trendelenburg position, ventricule and aortic root was punctured trans-septally with a $16 \mathrm{G}$ branule. Vent catheter was placed to right upper pulmonary vein. In case of defibrillation, external defibrilation pads were placed to the shoulder.

In seldinger guide technique chosen cases, after femoral artery and vein exploration, tapes were placed before punction for bleeding control. Descending thoracic aorta cannulation was made with inserting 0.038 guidewire (or hydrophilic guidewires in high fragil vessels) through $18 \mathrm{G}$ puncture needle (Figure 3 ). The venous cannula was sized and advanced externally as well as the right atrium. 16-18-20F artery cannulas were used according to patients Body Mass Index (BSA). In cannulation seldinger guide supported Femflex II (Edwards Lifesciences, Irvina, CA) or Medtronic Bio-Medicus ${ }^{\mathrm{TM}}$ NextGen percutanous femoral artery cannulas and venous Edwards ${ }^{\circledR}$ V Fem/Femoral (Edwards Lifesciences LLC, USA) cannulas were used. Tapes were removed for providing distal vascular perfusion. We evaluated the results retrospectively for cannulation techniques.

\section{Results}

65 patients ( 32 male, 33 female; mean age $43 \pm 37$ years; range 3-81 years) were taken into the study that peripheric femoral artery, vein and IJV cannulation performed for elective heart surgery between Novem-

Table 1.

\begin{tabular}{|l|c|c|c|}
\hline \multicolumn{1}{|c|}{ Number of Patients } & Number & Mean+SS & Min-Max \\
\hline Sex & 46 & & \\
\hline Male & 24 & \\
\hline Female & 22 & & \\
\hline Age & & $43 \pm 37$ & $3-81$ \\
\hline Body surface area & & $1.9 \pm 0.6$ & $1.2-4$ \\
\hline Body weight (Kg) & & $65 \pm 15.6$ & $35-100$ \\
\hline Ejection Fraction (\%) & & 54.629 & $20-70$ \\
\hline Aortic cros clamp time (Min) & & 90.47 & $28-187$ \\
\hline Bypass time (Min) & & 180.51 & $58-900$ \\
\hline
\end{tabular}


ber 2010- October 2017. For extracorporeal circulation sufficient perfusion was maintained through cannulas that were compatible with patients body surface area and vein diameter. Patients mean weight was $65 \pm 15.6$ $\mathrm{kg}$ (range $35-100 \mathrm{~kg}$ ) and mean body surface area was $1.9 \pm 0.6 \mathrm{~m} 2$ (range 1.2-4 m2). Patients demographics are shown in Table 1.

For 18 patients, minimally invazive technique was applied and 34 patients were redo cases. The operations are shown in Table 2. No pneumothorax or hemothorax were observed related to cannulation. Cannulas were placed successfully and sufficient venous drainage was maintained. In 4 patients( $\% 6.15)$, femorale venous cannulas couldn't advance to right atrium.

For these patients after sternotomy, two stage venous cannulas were placed into right atrium due to in- sufficient flow. All patients were operated with mean $4.108 \pm 0.6 \mathrm{~m} 2 \mathrm{1} / \mathrm{m} 2 / \mathrm{dk}$ flow rate. In 6 patients $(9.2 \%)$ vacuum (max:60 $\mathrm{mmHg}$ ) was applied for sufficient venous drainage. $70 \%$ of patients double peripheric venous cannulas were used.

Limb ischemia occured in 4 patients $(6.15 \%)$ who had open surgical peripheric cannulation performed. Therefore, due to distal thrombus, embolectomy was performed to those. No limb ischemia had occured in open seldinger and percutanous cannulation group.

Minimally invasive surgeries were performed via 13 ministernotomy and 5 minithoracotomy. In redo cases, neither signs of cardiac injury was observed nor hospital mortality. In postoperative follow-up, no hematoma was occured at IJV cannulation site. On the other hand, wound site complications at femoral cannulation site

Table 2.

\begin{tabular}{|c|c|c|c|c|c|c|}
\hline & \multicolumn{2}{|c|}{ Operation } & \multicolumn{2}{|c|}{ Redo operation } & \multicolumn{2}{|c|}{ Minimal invasive } \\
\hline & Number & Per. (\%) & Number & Per. (\%) & Number & Per. (\%) \\
\hline Total count & 65 & 100 & 34 & 52.3 & 18 & 27.6 \\
\hline Redo aortic valve replacement & & & & & - & \\
\hline Redo tricuspid valve replacement & & & & & - & \\
\hline Redo mitral valve replacement & & & & & - & \\
\hline Aortic valve replacement & 9 & & 6 & & 3 & \\
\hline Atrial septal defect repair & 5 & & - & & 5 & \\
\hline Mitral valve replacement & 23 & & 8 & & 8 & \\
\hline Rastelli & 1 & & - & & - & \\
\hline Heart transplant & 2 & & 2 & & - & \\
\hline Pulmonart valve replacement & 3 & & 3 & & - & \\
\hline Benthall & 6 & & 5 & & 1 & \\
\hline Assendan aort tubular greft & 5 & & 4 & & 1 & \\
\hline Thoracoabdominal aortic aneursym repair & 2 & & - & & - & \\
\hline Tricuspid valve replacement & 9 & & 7 & & 2 & \\
\hline Ventricular septal defect repair & 1 & & - & & 1 & \\
\hline
\end{tabular}


had occured in 4 patients $(6.15 \%)$ therefore revision operations were performed (hematoma in 2 patient, seroma in 2 patient). IVC repairment surgery was performed in 1 patient due to IVC injury during femoral vein cannulation.

The datas from this research were evaluated with database created with "Statistical Package for Social Sciences" (SPSS-Chicago, IL, USA) 16 and Software Excel (Microsoft-USA) programmes. Statistical analyses were made with same programmes. Measured values were evaluated with Mann Whitney U test, cathegorical values were evaluated with Fisher exact test. $p \leq 0.05$ values were excepted as significant.

\section{Discussion}

Nowadays minimally invasive approaches in cardiovascular surgery have become more popular by the means of increased quality of equipment. In cardiovascular surgery, percutanous cannulations frequently performed to ensure safer approach to redo cases, robotic and minimally invasive surgery. Optimal cannulation strategy for cardiovascular surgery has not determined yet. The decision varies from patients' clinical state and experience of surgery team. In this research, the results of open heart surgery cases with peripheric cannulation between November 2010 and June 2017 were evaluated retrospectively.

While peripheric cannulation performing, the cannulas stay out of surgical site thus, giving extra field for surgeon. ${ }^{(1-5)}$ By this means, smaller incisions can be

Figure 1.

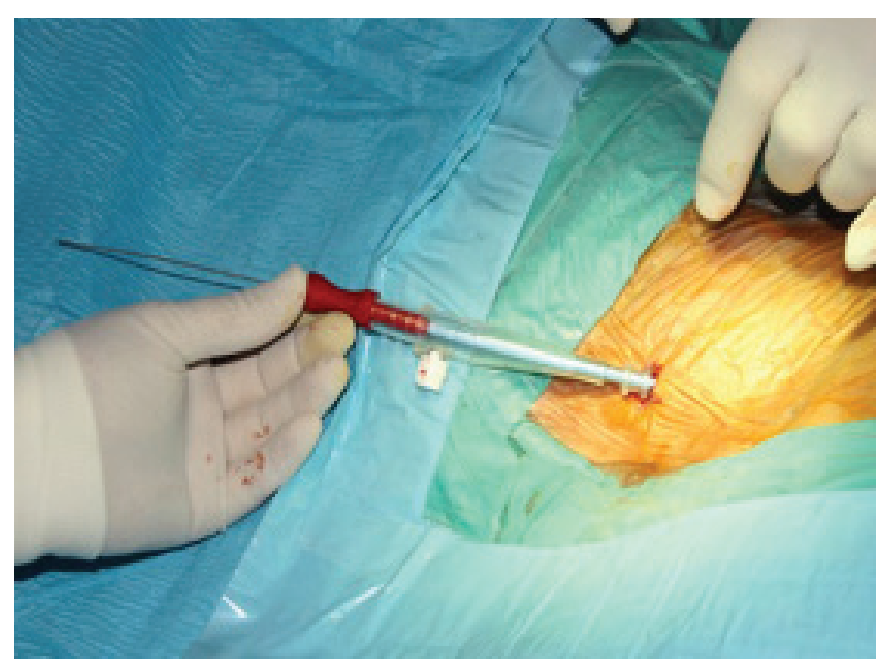

made. It enables both endoscopic view and port entry. It also provides CPB support before surgery so that surgical team can perform safely and faster. In the cases of thoracic surgeons who have a total circulatory arrest plan, the surgical team does not have to wait for cooling the patient by entering the pump in advance. Redo cases have high risk because of diffuse sternal attachment.

In these cases, performing peripheric cannulation before sternotomy provides reduction of ventricule tension by accumulating the blood partially into pump reservoir and decrase the risk of surgical bleeding. Cardiac dissection can be made comfortably. ${ }^{(1-7)}$ In case of high risk complications or abundant bleeding during exploration in redo cases, periferic cannulation also provides cerebral perfusion. ${ }^{(7-10)}$

Periferic cannulation can be performed easily with advanced technology. ${ }^{(11-12)}$ It can be made with seldinger technique, open or percutanous way as well as open arteriotomy, venotomy, proximal snaring and distal clamping. We recommend that the surgical seldinger method should also facilitates the bleeding control as well as maintaining of distal vascular perfusion can be also achieved by avoiding concervative distal clamping.

Standard surgical peripheral cannulation can also be achieved with minimally incision like in 1 or $2 \mathrm{~cm}$ lenght. When single peripheric venous cannulation is not enough, CPB vacuum support or double peripheric venous cannulation can be added. In these cases, CPB up to $60 \mathrm{mmHg}$ vacuum can be applied to the venous

Figure 2.

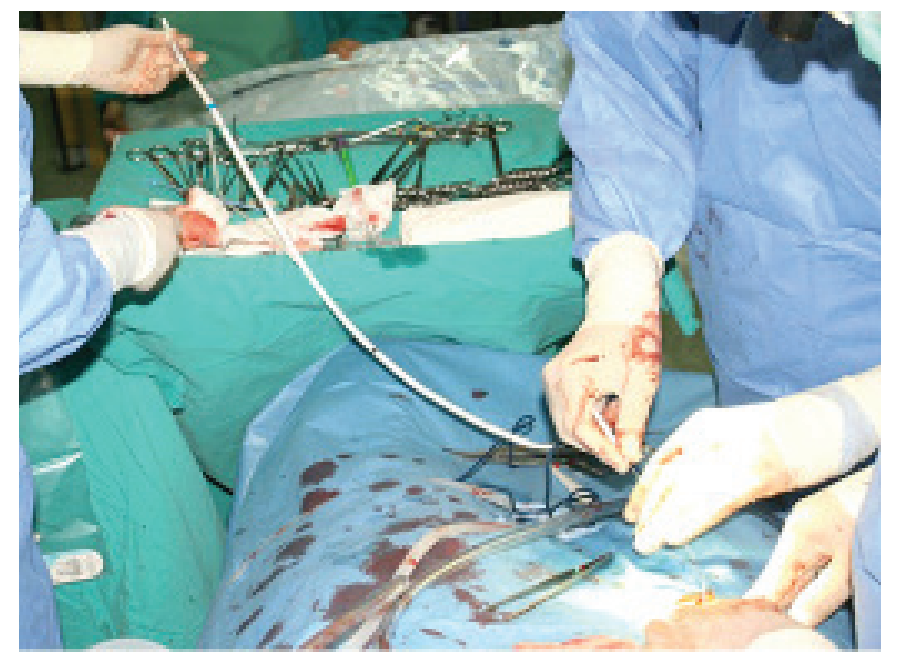


lines, thus the venous return can be increased.

In our study, $9.2 \%$ of patients were needed vacuum support while $70 \%$ of patients were needed double peripheric venous cannulas. Double venous cannulation enables short line and provides advantage in venous return for patients that have high BSA. In a research of Luciani and collegues, $20 \%$ of patients needed vacuum after percutanous cannulation. ${ }^{(15)}$ Since we applied a percutaneous jugular vein cannulation when is needed our vacuum application has reduced by the time (9.2\%).

IJV percutanous cannulation and snaring enables to perform cases via right atrium like atrial septal defect (ASD), ventricular septal defect, tricuspid valve replacement (TVR), atrial mass, atrial tumor-myxoma with only peripheric cannulation. Kitahara and col. evaluated ASD closing with right minithoracotomy for perfusion strategy in 91 patients, and determine that femoral artery cannulation is safer. ${ }^{(18)}$ It is advantageous to place cannulas percutanously using doppler usg before surgery. ${ }^{(11-12)}$ In our cases, IJV cannulations were performed by anesthesiologists without any complications. In literature it is implicated that anesthesiologists must take part in cannulation. ${ }^{(1-5)}$

In liver transplant cases IJV cannulation complication rate is reported in $0.32-0.7 \%$ mortality rate while we had no canulation related morbidity and mortality. By taking this into considiration we perform 20-22F cannulation carefully. We can perform more comfortably in open surgery with seldinger method.

Figure 3.

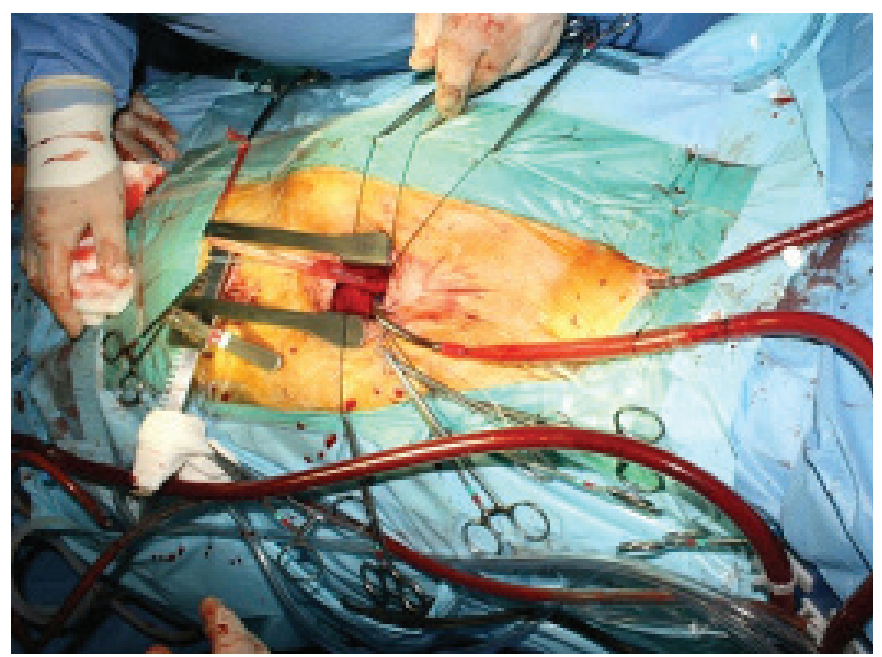

Keeping optimum and adequate venous return, a blood free and comfortable surgical site can be obtained. ${ }^{(1)}$ For femoral and IJV cannulations we try not to exagerate the size of cannulae by not exceeding optimal sizes. Accordingly in patients with fragile veins, we choose to use one size smaller cannulae and apply vacuum when is needed. Guidewires can cause temporary arrhythmia due to myocardial irritation.

Retracting guidewires 1-2 cm will prevent arrhythmias. We use Edwards ${ }^{\circledR}$ Lifesciences Fem Flex II and Medtronic Bio-Medicus ${ }^{\mathrm{TM}}$ NextGen percutanous femoral canulas for peripheric cannulation. ${ }^{(1-2)}$ Side hole and flexible structure are advantages of the cannulas. They are compatible for venous drainage. We choose cannulas according to patients neck and body length. For patients with short neck we use one size smaller cannulas. During cannulation, the neck is deviated to the counter side, sholders closed with trendelenburg position.

Axillar cannulation method in complicated cases with aortic surgery; Neurocognitive outcomes are better reported. Antegrade provides perfusion convenience. It is preferred today. ${ }^{(2-4)}$ Axillary artery is recommended not to be preferred in cases of small arterial diameter because of diminished limb perfusion. ${ }^{(2-8)}$ Central arterial monitoring is also not recommended in cases of distress. ${ }^{(1-3)}$ Brachial plexus injury has been reported in the literature recently. ${ }^{(2-6)}$

Femoral cannulation is a perfect choice for open heart surgeries and CPB. We evaluated cases with IJJV seldinger cannulation, femoral artery-vein both open and seldinger cannulations. Recently, due to innovations in cannulation and perfusion technologies, seldinger guide technique is used in peripheric cannulation for heart surgery. Minimal dissection is usually sufficient. In seldinger guide femoral cannulation, there is no need for arteriotomy after exploration, by this way distal extremity perfusion is maintained. Besides this method is easy to apply percutanously and also by surgical exploration.

Moreover, decannulation can be also performed fastly and safely. In percutan decannulation, about 10 min compression after protamine neutralization is usually enough. Cosmetic results are satisfying for patient. 
After open surgery seldinger cannulation, entry hole can be closed with primer sutures. Our study with 65 patients supports these results.

Extremity ischemia occured in 4 patients $(6.15 \%)$ that open surgery peripheric cannulation performed, and due to distal thrombus, embolectomy was performed. No limb ischemia had occured in seldinger open and percutanous cannulation group. In addition to these study remarks, limb perfusion can be provided in seldinger technique that stabilized with only hanger tape without need of clamp or snare.

Perioperative evaluation with doppler usg and positioning cannulas that allows optimal CPB perfusion flow are the most important matters. Patients must be evaluated for severe atherosclerosis, unstable plaque, mobile thrombus, vascular occlusion with lung $\mathrm{X}$ rays, echocardiography, tomography and angiograms preoperatively. Minimally vascular surgical manipulation and exploration can prevent trauma and perivascular lymph leakage. By this means risks of seroma formation and wound site infections can be minimized.

Suitable size and type of cannulas must be chosen in compliance to vessel quality. For fragile vessels Edwards ${ }^{\circledR}$ Fem-Flex II percutan femoral artery cannulas can be used safely. Guidewires must be checked whether it advances intavascularly, in case of hesitation, vascular positioninig must be performed with the help of $\mathrm{X}$ ray-scopy intraoperatively. Placement of venous cannulas must be checked with palpation after sternotomy and exploration.

Vida and col. suggests that right jugular vein cannulation and femoral artery open surgery cannulation is the optimal choice for patients above $15 \mathrm{~kg}$. ${ }^{(16)}$ The same study suggests that peripheric cannulation decreases the amount of surgical stress. Reeb and col. suggests that peripheric cannulation is practical for elective or emergency ECMO applications. ${ }^{(17)}$

Vallabhajosyula and col. report that superficial femoral artery percutanous cannulation doesn't increase the rate of extremity ischemia with a 92 patient study. ${ }^{(18)}$

They also suggest that distal perfusion must be checked with angiogram. Von Segesser and col. evaluated results of 407 patients that had been performed venoatrieal ECMO. ${ }^{(20)}$ Ischemic complication rate is reported as $11-52 \%$, need for surgical repair rate is $9-22 \%$, leg amputation rate is reported as $2-10 \%$. This study higlighted to watch out peripheral ischemia in arterial cannulation and to choose smaller diameter cannulas. And use of double way artery cannulas are suggested for maintaining the reperfusion.

There is no limitation in our randomized study because of retrospective evaluation. Our evaluation is unbiased because operations had been performed with same surgical and anesthesiologist team.

\section{Conclusion}

In the light of our study; we suggest that peripheric or percutaous cannulation provides a specific advantage in 'redo cases' besides the well known indications in minimally invasive heart surgery, aortic dissection and robotic heart surgery. Low morbidity and mortality can be achieved especially in even most difficult redo cases when peripheral cannulation performed prior to sternotomy. On pump sternotomy also brings the advantage of empting of right ventricule and atrium that reduces wall tension and risk of accidential rupture during the sternotomy. In emergency CPB and ECMO cases, femoral artery-vein and IJV peripheric cannulation with seldinger guide can also be performed rapidly and safely. 


\section{References}

1. Maltepe F, Metin K, Hepaguslar H, Hanc1 V, Ugurlu B, Oto O. Perkütan internal jugüler ven kanülasyonu ile kalp cerrahisi. Türk Göğüs Kalp Damar Cerrahisi Dergisi 2013;21(4):959-65.

2. Tsiouris A, Elkinany S, Ziganshin BA, Elefteriades JA. Open SeldingerGuided Femoral Artery Cannulation Technique for Thoracic Aortic Surgery. Ann Thorac Surg 2016;101(6):2231-5.

3. Gobolos L, Ugocsai P, Foltan M, Philipp A, Thrum A, Miskolczi S, et al. Central cannulation by Seldinger technique: a reliable method in ascending aorta and aortic arch replacement. Med Sci Monit 2014;(22),20:2386-93.

4. Ludwig K, Segesser V. Peripheral cannulation for cardiopulmonary bypass. Multimedia Manual of Cardiothoracic Surgery, 2006 European Association for Cardio-Thoracic Surgery 2006;(1);1009:mmcts-001610.

5. Turker G, Kaya FN, Gurbet A, Aksu H, Erdogan C, Atlas A. Internal jugular vein cannulation: an ultrasound-guided technique versus a landmark-guided technique. Clinics (Sao Paulo) 2009;64:989-92.

6. Reeb J, Olland A, Renaud S, Lejay A, Santelmo N, Massard G, et al. Vascular access for extracorporeal life support: tips and tricks. J Thorac Dis 2016;8(Suppl 4):S353-63.

7. Kitahara H, Okamoto K, Kudo M, Yoshitake A, Ito T, Hayashi K, et al. Alternative peripheral perfusion strategies for safe cardiopulmonary bypass in atrial septal defect closure via a right minithoracotomy approach. Gen Thorac Cardiovasc Surg 2016;64(3):131-7.

8. Sabik JF, Nemeh H, Lytle BW, et al. Cannulation of the axillary artery with a side graft reduces morbidity. Ann Thorac Surg 2004;77(4):1315-20.

9. Xu RB, Pese K, Stuklis R, Edwards J. Peripheral Cannulation for Cardiopulmonary Bypass in Resection of Renal Cell Carcinomas with Level 3 Tumour Thrombus. Heart Lung Circ 2016;25(3):e56-8.

10. Senay S. Cannulation techniques in aortic surgery. Multimed Man Cardiothorac Surg 2015;8. pii: mmv019.

11. Troianos CA, Hartman GS, Glas KE, Walker JD, et al. Guidelines for performing ultrasound guided vascular cannulation: recommendations of the American Society of Echocardiography and the Society of Cardiovascular Anesthesiologists. J Am Soc Echocardiogr 2011;24:1291-318.

12. Mitre CI, Golea A, Acalovschi I, Mocan T, Caea AM, Ruta C, et al. Ultrasound-guided external jugular vein cannulation for central venous access by inexperienced trainees. Eur J Anaesthesiol 2010;27:300-3.

13. Budd JM, Isaac JL, Bennett J, Freeman JW. Morbidity and mortality associated with large-bore percutaneous venovenous bypass cannulation for 312 orthotopic liver transplantations. Liver Transpl 2001;7:359-62.

14. Navarro F, Le Moine MC, Fabre JM, Belghiti J, Cherqui D, Adam R, et al. Specific vascular complications of orthotopic liver transplantation with preservation of the retrohepatic vena cava: review of 1361 cases. Transplantation 1999;68:646-50.

15. Luciani N, Anselmi A, De Geest R, Martinelli L, Perisano M, Possati G. Extracorporeal circulation by peripheral cannulation before redo sternotomy: indications and results. J Thorac Cardiovasc Surg 2008;136:572-7.

16. Vida VL, Tessari C, Putzu A, Tiberio I, Guariento A, Gallo M, et al. The peripheral cannulation technique in minimallyly invasive congenital cardiac surgery. Int J Artif Organs 2016;(6),8:0.

17. Reeb J, Olland A, Renaud S, Lejay A, Santelmo N, Massard G, et al. Vascular access for extracorporeal life support: tips and tricks. J Thorac Dis 2016;8:S353-63.

18. Kitahara H, Okamoto K, Kudo M, Yoshitake A, Ito T, Hayashi K, et al Alternative peripheral perfusion strategies for safe cardiopulmonary bypass in atrial septal defect closure via a right minithoracotomy approach. Gen Thorac Cardiovasc Surg 2016;64(3):131-7.

19. Vallabhajosyula P, Kramer M, Lazar S, McCarthy F, Rame E, Wald J, et al. Lower-extremity complications with femoral extracorporeal life support. J Thorac Cardiovasc Surg 2016;151(6):1738-44.

20. Von Segesser L, Marinakis S, Berdajs D, Ferrari E, Wilhelm M, Maisano F. Prevention and therapy of leg ischaemia in extracorporeal life support and extracorporeal membrane oxygenation with peripheral cannulation. Swiss Med Wkly 2016;146:w14304.

Received: $12 / 11 / 2017$

Accepted: 06/03/2018

Published: 15/03/2018

Disclosure and conflicts of interest:

The authors declare no conflict of interest.

\section{Corresponding author:}

Tuğra Gençpınar

Mail: tugra01@yahoo.com 